\title{
Initial speaking distance as a function of the speakers' relationship
}

FRANK N. WILLIS, JR.

Distances between individuals were recorded at the moment conversation began. The distances were then related to the relationship between the individuals and to their sex, age and race. Groups differing in these characteristics were found to differ reliably in initial speaking distance. Student experimenters were approached more closely by their friends than by their parents whose approach was similar to that of strangers. Speaking distance was suggested as part of an operational definition of interpersonal relations.

The use of space is important in the interaction of animals. Hediger (1955) stated that the communication distance between animals varies depending upon the species. Communication distance among humans has also received some attention. Hall (1955) reported that Americans will not stand closer than 18-20 in. when talking to strangers of the same sex, while people from the Middle East or from Latin America stand much closer. Argyle \& Dean (1956) found that the distance in social interaction is related to eye contact and to age. Ss approached an experimenter more closely when his eyes were closed and children approached more closely than adults. Sommer $(1959,1962)$ determined the comfortable seated speaking distance. In the first study he found that women tend to sit more closely than men. Hall (1959) reported that seating distance varies with the intimacy among people. Up to the present time standing speaking distances have not been specified nor have exact speaking distances been reported for pairs of individuals as a function of their relationship. One can determine from casual observation that standing speaking distance is not constant but varies during interaction.

The purpose of the present study was to describe with some precision standing speaking distance at the initiation of natural interaction.

\section{Method}

Subjects. An incidental sample of 755 Ss was obtained in homes, places of business, and in the halls of the University.

Apparatus. Each E carried a cloth tape measure which was used to obtain initial speaking distances in inches.

Procedure. Forty Es were instructed to obtain 20 initial speaking distances each, using the following procedure: when approached by anyone who began a conversation Es remained at a fixed point. The moment conversation was begun $E$ measured the distance from nose to nose between $S$ and $E$. E then recorded the sex, age and race of the $S$ and the relationship between $S$ and E. Relationship categories were defined as follows: a stranger-an S whom $\mathrm{E}$ had never met; acquaintance- an
$\mathrm{S}$ whom $\mathrm{E}$ had perhaps met but does not greet by name; friend-an $S$ whom $E$ greets or addresses by name; close friend-reserved for E's best same-sexed friends or in the case of opposite-sexed pairs those who dated, who were engaged or were married. Relatives of $\mathrm{E}$ were identified in terms of the specific relationship. Three age groupings were used, older, younger, or peer (age within ten years of E). Analyses of the data were made by matching Ss on all recorded characteristics other than those in the particular analysis. The groups differed considerably in size so that matching often involved random drawing from a larger group in order to make a particular comparison. In spite of the relatively large number of total observations, division into age, sex, race and relationship categories resulted in a number of subgroups with Ns too small to permit several analyses. The exploratory nature of the study resulted in the decision to report differences reliable at $\mathrm{p} \leq .10$ with a two-tailed test.

\section{Results}

Sex and relationship. Speaking distance as a function of the sex of the speaker, the sex of the listener, and their relationship was examined with the analysis of variance summarized in Table 1 . All Ss and Es in this analysis were Caucasian and were peers. Small Ns necessitated the elimination of other relationship categories with this race, age, and sex combination. Women were approached more closely than men (mean $=21.58 \mathrm{in}$. for women and $24.46 \mathrm{in.} \mathrm{for} \mathrm{men).} \mathrm{Means} \mathrm{for} \mathrm{the} \mathrm{inter-}$ action of sex of speaker and relationship for men: acquaintances 23.75 in., friends $22.31 \mathrm{in.,}$ and close friends 23.08 in. Means for women were: acquaintances 22.41 in., friends 26.17 in., and close friends 17.75 in. Women stand quite close to good friends when speaking but stand back from those they describe as friends.

Age and relationship: An adequate number of observations for an age group comparison was available in only two relationship categories, acquaintance and

Table 1. Analysis of Variance of speaking distances for Sex of Speaker, Sex of Listener, and Relationship

\begin{tabular}{lrrrr} 
Source & \multicolumn{1}{c}{ SS } & df & \multicolumn{1}{c}{ MS } & \multicolumn{1}{c}{$F$} \\
\hline Sex of Speaker (S) & 3.03 & 1 & 3.08 & - \\
Sex of Listener (L) & 562.05 & 1 & 562.05 & $10.31^{* *}$ \\
Relationship (R) & 468.52 & 2 & 234.26 & $4.30^{*}$ \\
SX L & 30.45 & 1 & 30.45 & - \\
SXR & 752.55 & 2 & 376.28 & $6.90^{* *}$ \\
RX L & 12.99 & 2 & 6.49 & - \\
SXRX L & 23.00 & 2 & 11.50 & - \\
Within groups & 14178.26 & 260 & 54.53 & \\
\hline
\end{tabular}

* $p<.05 \quad * * 0<.01$ 
stranger. All Es and Ss in this analysis were Caucasian. An analysis of variance for a two by two factorial design with unequal Ns (Scheffe, 1959,p. 116) yielded an $F=6.77$ for age with $p<.05$. The $F$ for relationship was 4.51 with $\mathrm{p}<.05$. The interaction was not significant. The means were: peers 23.87 in., older 26.67 in., acquaintances 23.80 in., and strangers 27.33 in.

Parents. The sample contained 38 parents of the Es. Since age was found to be related to speaking distance, parents were compared to older relationship groups. Twenty-two parents were compared with a group of 22 friends and good friends. The two groups were matched for sex of speaker and sex of listener. A Mann-Whitney $U$ analysis yielded a $U=363.5$, equivalent to a $Z=2.84$ with $\mathrm{p}<.05$. Median speaking distances for the groups were: parents 26 in. and friends-good friends 19.5 in. Twenty-five parents were matched with 25 strangers for sex of speaker and sex of listener. The distributions of speaking distances were strikingly similar with identical medians of $27 \mathrm{in.}$

Race. Two groups of nine observations one with Caucasian to Caucasian and the other with Caucasian to Negro were matched for age group and sex. A MannWhitney $U$ analysis yielded a $U=20.5$ with $p=.10$. The Caucasian to Caucasian median was 22 in. and the Caucasian to Negro median was 28 in. Two groups of 30 observations one with Caucasian to Caucasian and the other with Negro to Negro were matched for age group and sex. A Mann-Whitney $U$ analysis yielded a $\mathrm{U}=113.5$, equivalent to a $\mathrm{Z}=1.68$ with $\mathrm{p}<.09$. The Caucasian to Caucasian median was 22.5 in. and the Negro to Negro median was 24 in. A third comparison involving a Caucasian to Caucasian group and a Negro to Caucasian group did not yield a $\mathrm{U}$ with $\mathrm{p} \leq .10$.

\section{Discussion}

The results of this study indicate that the relationship between two people is reflected in their use of space. Speakers tend to stand more closely to women than to men. Compared with men, women stand more closely to good friends but further from those they describe as friends. Perhaps women tend to be more cautious until close relationships are established. Peers stand closer than do persons older than the listener. Strangers begin conversations at distances greater than that of acquaintances. There was some evidence that both Negroes and Caucasians tend to stand farther from Negroes than they do from Caucasians. Most of these results are not surprising. Our choice of physical terms to describe relationships (close, distant) perhaps stems from our actual use of space in interacting. One result, however, does appear somewhat surprising. We might expect parents to approach their children in a manner similar to the approach of the children's friends. We find, however, that they are as "distant" as strangers.

Past generalizations about Americans in their use of space in interaction seem to be inaccurate. Speaking distances vary sufficiently among sub-groups of Americans that statements about Americans appear meaningless.

Several important issues in the area of speaking distance remain unexamined. All Es in this study were University students. Different receivers might well produce different results. Setting and topic of conversation were similarly ignored in this study. A method of continuous recording of speaking distance would be valuable in evaluating speech content and distance.

Initial speaking distance appears to be an important dimension of interaction and might be employed as part of an operational definition of interpersonal relationship. An examination of the use of space in interaction could profitably be used as part of an action approach to the study of prejudice and inter-group relations.

\section{References}

Argyle, M., \& Dean, Janet. Eye-contact, distance, and affiliation. Sociometry, 1965, 28, 289-304.

Hall, E. T. The anthropology of manners. Scientific American. $1955,192,84-90$.

Hall, E. T. The Silent Language. Garden City: Doubleday, 1959. Scheffe, H. The analysis of variance. New York: Wiley, 1959. Sommer, R. Studies in personal space. Sociometry, 1959, 22, 247260.

Sommer, R. The distance for comfortable conversation: A further study. Sociometry, 1962, 25, 111-116. 